СИНТЕЗ, СТРОЕНИЕ И СВОЙСТВА КОМПЛЕКСНЫХ СОЕДИНЕНИЙ АНТАНОИДОВ С 4-[(3,4-ДИМЕТОКСИБЕНЗИЛ) АМИНО] БЕНЗОЙНОЙ КИСЛОТОЙ.

\author{
Шамсутдинова Медина Хумаидовна \\ кандидат хим. наук, доцент кафедры химии, \\ ФГБОУ ВО «Чеченский государственный университет» \\ г. Грозный \\ Ильхаева Зара Султановна \\ старший преподаватель кафедры химии \\ ФГБОУ ВО «Чеченский государственный университет» \\ 2. Грозный \\ Хасаева Алет Ильясовна \\ 4 курс «микробиология» \\ ФГБОУ ВО «Чеченский государственный университет» \\ 2. Грозный
}

\title{
SYNTHESIS, STRUCTURE AND PROPERTIES OF COMPLEX COMPOUNDS OF ANTHANOIDS WITH 4 - [(3,4-DIMETOXYBENZYL) AMINO] BENZOIC ACID.
}

\author{
Shamsutdinova Medina Humaidovna \\ Candidate of the Chemical Sciences, \\ Associate Professor of the Department of Chemistry, \\ FGBOU VO "Chechen State University", Grozny \\ Ilkhaeva Zara Sultanovna \\ Senior Lecturer, Department of Chemistry \\ FSBEI HE "Chechen State University" \\ Grozny \\ Khasaeva Alet Ilyasovna \\ 4 course "microbiology" \\ FSBEI HE "Chechen State University" \\ Grozny \\ DOI: 10.31618/ESU.2413-9335.2020.6.76.940
}

\section{АННОТАЦИЯ}

Проведен синтез комплексных соединений 4-[(3,4- диметоксибензил)амино] бензойной кислоты (HL) с ионами самария(III), европия(III), тербия(III), гадолиния(III) и диспрозия(III). Согласно данным элементного анализа и термогравиметрии полученные комплексы представляют собой гидраты состава $\mathrm{LnL}_{3} \cdot \mathrm{nH}_{2} \mathrm{O}$, где $\mathrm{n}=0-2$. Область их термостабильности в пределах от $100^{\circ} \mathrm{C}$ до $150^{\circ} \mathrm{C}$. Измерены электронные и инфракрасные спектры поглощения лиганда и комплексов с ионами редкоземельных металлов. По данным ИК спектров координация лиганда с ионом металла осуществляется по карбоксильной группе. Карбоксильная группа координирована бидентатно. Для возбуждения люминесценции использована линия ртутной лампы с длиной волны 248 нм. Наибольшая интенсивность люминесценции наблюдается для координационных соединений $\mathrm{Eu}^{3+}, \mathrm{Tb}^{3+}, \mathrm{Sm}^{3+}$ и $\mathrm{Dy}^{3+}$.

\section{ANNOTATION}

The synthesis of complex compounds of 4 - [(3,4-dimethoxybenzyl) amino] benzoic acid (HL) with ions of samarium (III), europium (III), terbium (III), gadolinium (III) and dysprosium (III). According to the data of elemental analysis and thermogravimetry, the obtained complexes are hydrates of the composition $\mathrm{LnL} 3 \cdot \mathrm{nH} 2 \mathrm{O}$, where $\mathrm{n}=0-2$. The area of their thermal stability is in the range from $100^{\circ} \mathrm{C}$ to $150^{\circ} \mathrm{C}$. Electronic and infrared absorption spectra of the ligand and complexes with rare-earth metal ions have been measured. According to the IR spectra, the coordination of the ligand with the metal ion occurs at the carboxyl group. The carboxyl group is bidentate coordinated. To excite luminescence, a line of a mercury lamp with a wavelength of $248 \mathrm{~nm}$ was used. The highest luminescence intensity is observed for the coordination compounds Eu3 +, Tb3 +, Sm $3+$, and Dy $3+$.

Ключевые слова: комплексы лантаноидов, термограмма, УФ спектры, ИК спектры, люминесценция.

Key words: lanthanide complexes, thermogram, UV spectra, IR spectra, luminescence.

Актуальность темы: Ежегодно в научной литературе увеличивается число публикаций, посвященных люминесцирующим комплексным соединениям лантаноидов с органическими лигандами и их практическому применению в различных отраслях науки и промышленности. Люминесценция координационных соединений лантаноидов с органическими лигандами нашла широкое применение в различных областях науки и техники в качестве защитных покрытий[1], люминесцентных зондов[2], сигнальной части в хемосенсорах[3].Одним из важнейших практических направлений является использование комплексов лантаноидов в качестве 
светоизлучающего слоя в органических светоизлучающих диодах(ОСИД), лазерах[4].

ОСИД- это устройства, в которых в результате явления электролюминесценции электрическая энергия преобразуется в световое излучение. Одними из типов ОСИД являются органические светодиоды на так называемых малых молекулахкомплексных соединениях, красителях и др.Возрастающее число исследований в этой области показывает перспективность использования ОСИД на основе комплексных соединений лантаноидов.. Это связано с тем, что степень преобразования энергии при использовании триплетных эмиттеров может достигать $100 \%$, а помимо дорогостоящих металлорганических соединений (иридия, рутения и других редких металлов платиновой группы) к таким люминофорам относятся и координационные соединения лантаноидов. В отличие от металлов платиновой группы каждый ион лантаноида имеет характерный уникальный спектр испускания, положение пиков в котором при смене лигандов практически не изменяется, изменяется только интенсивность и характер (расщепление) спектров. Таким образом, задача поиска новых люминесцирующих комплексных соединений сводится к подбору лиганда (высокой вероятности образования триплетного уровня, его оптимального расположения по отношению к излучающему уровню лантаноида, хорошей координирующей способности) для каждого иона лантаноида. Другим преимуществом комплексов лантаноидов является малая ширина полос испускания в спектрах люминесценции, в отличие от широких полос в спектрах органических соединений и комплексов d-металлов, что позволяет получать относительно «чистые» цвета и делает перспективным применение ОСИД на основе комплексов лантаноидов в системах отображении информации.
В литературе описаны исследования люминесцентных свойств комплексных соединений лантаноидов с орто-, мета- и парааминобензойными кислотами и их производными, а также изготовление на их основе прототипов ОСИД устройств. Введение заместителей в аминогруппу пара-аминобензойной кислоты может существенно повысить люминесцентные характеристики получаемых комплексных соединений, а также растворимость металлокомплексов в органических растворителях, что позволит упростить их дальнейшее использование в качестве светоэмиссионного слоя в ОСИД.

В связи с этим цель настоящей работы синтез и изучение люминесцентных свойств координационных соединений лантаноидов, люминесцирующих в видимой спектральной области, с такой $\mathrm{N}$-замещенной карбоновой кислотой как 4-[(3,4-

диметоксибензил)амино]бензойной кислотой.

Bce координационные соединения синтезированы из водно-спиртовых растворов, содержащих соль металла и лиганд в соотношении $\mathrm{Ln}: \mathrm{HL}=1: 3$. Так как лантаноиды легче образуют комплексы с ионизированной карбоксильной группой, то при синтезе значение $\mathrm{pH}$ раствора поддерживали более 5.0 добавлением щелочи или использованием предварительно полученной калиевой соли лиганда. Во избежание образования гидроксокомплексов лантаноидов рН при синтезе не превыстставлены полученные комплексы представляют собой гидраты состава $\mathrm{LnL}_{3} \cdot \mathrm{nH}_{2} \mathrm{O}$, где $\mathrm{n}=0-2$. После сушки в вакуумной печи некоторых комплексов получали безводные соединения. Данные элементного анализа представлены в таблице 1 .

Данные анализа состава комплексов с HL.

\begin{tabular}{|c|c|c|c|c|c|}
\hline \multirow{2}{*}{ Комплекс } & \multirow{2}{*}{ Формула } & \multirow{2}{*}{$\mathrm{T}_{\text {пл., }}{ }^{\circ} \mathrm{C}$} & \multicolumn{3}{|c|}{ Содержание элемента, \% } \\
\cline { 4 - 6 } & & 246 & 80,3 & 0 & L2 \\
\hline $\mathrm{Eu}(\mathrm{L})_{3}$ & $\mathrm{C}_{36} \mathrm{H}_{45} \mathrm{EuO}_{9}$ & 235 & 80,5 & 0 & 19,7 \\
\hline $\mathrm{Sm}(\mathrm{L})_{3} \cdot$ & $\mathrm{C}_{36} \mathrm{H}_{45} \mathrm{SmO}_{9}$ & 247 & 77,8 & 2,3 & 19,9 \\
\hline $\mathrm{Tb}(\mathrm{L})_{3} \cdot \mathrm{H}_{2} \mathrm{O}$ & $\mathrm{C}_{36} \mathrm{H}_{47} \mathrm{TbO}_{10}$ & 247 & 0 & 21,2 \\
\hline $\mathrm{Gd}(\mathrm{L})_{3}$ & $\mathrm{C}_{36} \mathrm{H}_{45} \mathrm{GdO}_{9}$ & 233 & 79,8 & 0 & 20,3 \\
\hline $\mathrm{Dy}(\mathrm{L})_{3} \cdot \mathrm{H}_{2} \mathrm{O}$ & $\mathrm{C}_{36} \mathrm{H}_{47} \mathrm{DyO}_{10}$ & 240 & 77,5 & 2,2 & \\
\hline
\end{tabular}

При синтезе новых координационных соединений очень важно исследовать их термическую устойчивость - характер дегидратации, область термостабильности, температуры плавления и разложения. Также при возможном применении веществ в технике важно знать температурный диапазон работы материалов. При изготовлении электролюминесцентных устройств комплексные соединения наносят вакуумной сублимацией при нагревании, поэтому необходимо исследовать области термостабильности

соединений. Термогравиметрический анализ проводили на приборе NetzchSTAв области $20-1000^{\circ} \mathrm{C}$, в атмосфере аргона, скорость нагрева от 2 до $10^{\circ} \mathrm{C}$ в минуту. Термограмма комплекса $\operatorname{Eu}(\mathrm{L})_{3}$ представлена на рисунке 1.

Комплексные соединения с HL уже при сушке без вакуума полностью обезвоживались.На термограмме при температуре $140^{\circ} \mathrm{C}$ наблюдается эффект , соответствующий дегидратации комплекса. При температуре около $330^{\circ} \mathrm{C}$ 
наблюдается эндоэффект без потери массы, что соответствует плавлению вещества, свыше $400^{\circ} \mathrm{C}$ идет термолиз комплекса.

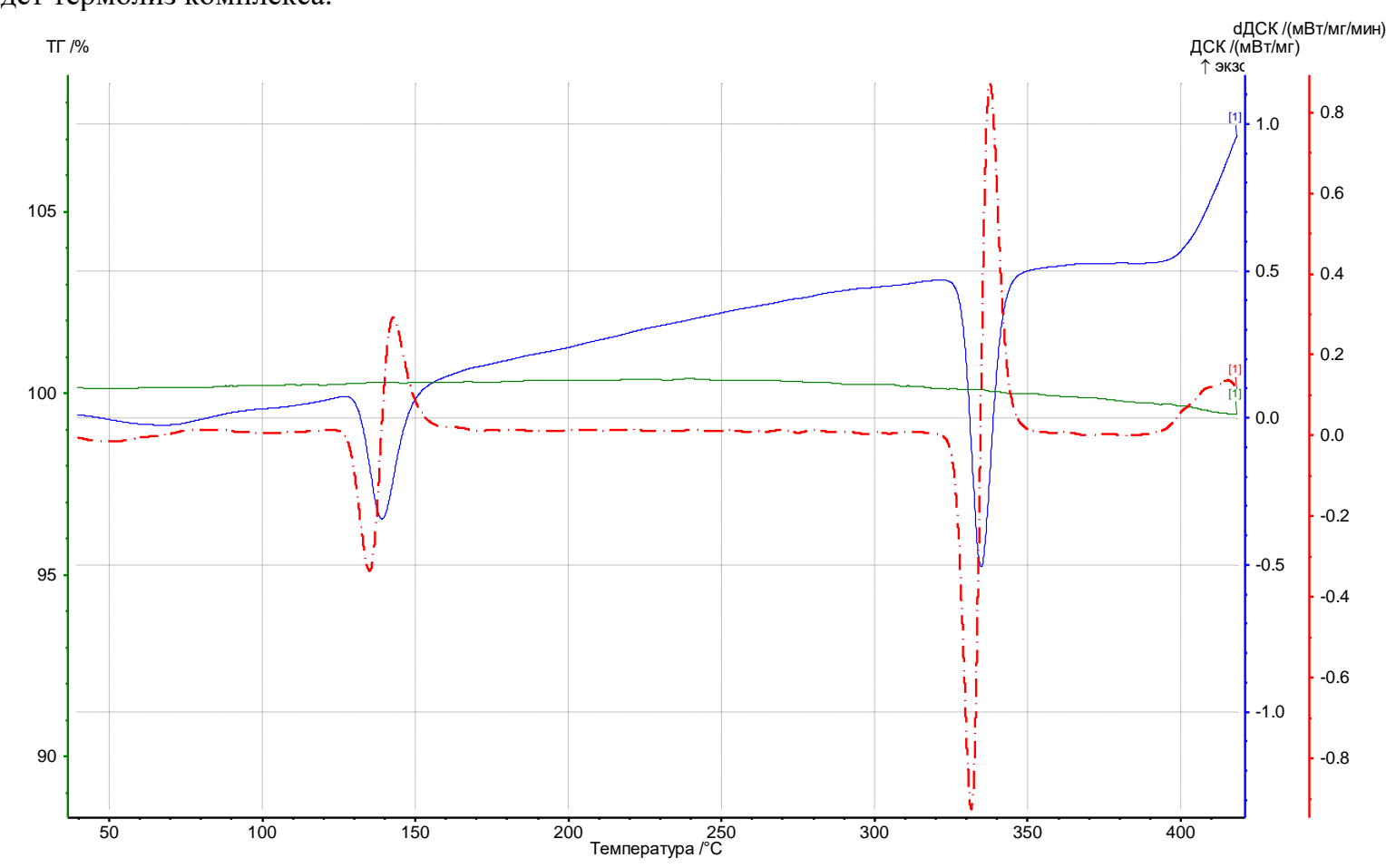

Рисунок1. Термограмма комплекса Еu(L)3

Исследование термограмм комплексов с другими металлами показало, что термостабильность в ряду лантаноидов существенно не изменяется. Комплексные соединения с HL можно отметить, как термически устойчивые.

Электронные спектры поглощения записывали на двухлучевом спектрометре М 40 с модулем подключения к персональному компьютеру в кварцевых кюветах с толщиной пропускающего слоя 1 см в диапазоне $50000-11000 \mathrm{~cm}^{-1}$. В качестве растворителей использовали этанол, тетрагидрофуран, метанол и ацетон.

Инфракрасные спектры регистрированы на серийном фурье-спектрометре «ИНФРАЛЮМ ФТ-02» в диапазоне волновых чисел $4000-350 \mathrm{~cm}^{-}$ ${ }^{1}$.Образцы готовили прессованием таблеток под вакуумом (до 2 мм. рт. ст.), содержащие 1 мг образца и 100 мг KBr. .

Спектры люминесценции твердых образцов записывалны на спектрометре SPEXRamalog в режиме счета фотонов. В качестве источников возбуждения использованы азотный лазер с длиной волны 337 нм и ртутную лампу сверхвысокого давления ДРШ-250. Регистрацию люминесценции проводили при комнатной температуре в диапазоне $29500-13000 \mathrm{~cm}^{-1}$.

Спектры координационных соединений разных металлов с данным лигандом практически не отличаются, поэтому анализ ИК спектров был проведен на примере гадолиниевых комплексов. (табл.3)

В ИК спектрах всех координационных соединений в отличие от спектра лиганда отсутствует полоса поглощения валентных колебаний связи $\mathrm{C}=\mathrm{O}$ карбоксильной группы и наблюдается появление полос поглощения валентных симметричных и ассиметричных колебаний депротонированной карбоксильной группы, что свидетельствует о полном депротонировании карбоксильной группы лиганда. Для определения дентатности широко используется разность $\Delta v\left(\mathrm{COO}^{-}\right)=v_{a s}\left(\mathrm{COO}^{-}\right)-$ $v_{\mathrm{S}}\left(\mathrm{COO}^{-}\right)$. Результаты сравнения значения $\Delta v\left(\mathrm{COO}^{-}\right.$ ) для комплексных соединений с HL и калиевых солей указанного лиганда (табл.3) показывают, что в комплексах $\mathrm{Gd}(\mathrm{L})$ карбоксильная группа координирована бидентатно, так как значение $\Delta v\left(\mathrm{COO}^{-}\right)$для комплексов менее $200 \mathrm{~cm}^{-1}$. Смещение характеристичных полос поглощения других функциональных групп $(v(\mathrm{C}=\mathrm{N}), \mathrm{v}(\mathrm{C}-\mathrm{O})$ в спектрах комплексов не происходит, что говорит о неучастии эфирного кислорода и атома азота в координации.

Значение коэффициента экстинкции полос поглощения органических лигандов определяет их поглощающую способность и может достигать нескольких десятков тысяч. Благодаря этому эффективность люминесценции ионов лантаноидов увеличивается на несколько порядков и теоретически может достигать 100\%. Для определения поглощающей способности лиганда нами были записаны электронные спектры поглощения в спиртовых растворах. Были получены следующие параметры электронных спектров лиганда HL-253нм (11600),283нм (1140). 
Как видно, лиганд обладает сравнительно хорошей поглощающей способностью и для возбуждения люминесценции достаточно использовать линию ртутной лампы с длиной волны 248 нм.

У всех синтезированных комплексных соединений с данным лигандом наблюдается люминесценция ионов лантаноидов, при этом фосфоресценция органического лиганда отсутствует, что говорит о хорошей передаче энергии от лиганда иону лантаноида.

Наибольшая интенсивность люминесценции наблюдается для комплексных соединений $\mathrm{Eu}^{3+}$, $\mathrm{Tb}^{3+}, \mathrm{Sm}^{3+}$ и $\mathrm{Dy}^{3+}$ (рис.7-9).Одинаковый характер полос испускания и их положения в спектрах люминесценции комплексов с данным лигандом свидетельствует об одинаковой симметрии центров люминесценции, следовательно, об одинаковой структуре координационного узла. Спектры люминесценции лантаноидов различаются только по интенсивности.

\section{Выводы}

1. Получены комплексные соединения $\mathrm{Sm}^{3+}, \quad \mathrm{Eu}^{3+}, \quad \mathrm{Gd}^{3+}, \quad \mathrm{Tb}^{3+}, \quad \mathrm{Dy}^{3+} \quad \mathrm{c} \quad 4-[(3,4-$ диметоксибензил)амино]бензойной кислотой (HL), состав которых соответствует формуле $\mathrm{LnL}_{3} \mathrm{nH}_{2} \mathrm{O}$, где $\mathrm{n}=0-2$.

2.Методом термогравиметрии определены области термостабильности комплексных соединений: для $\operatorname{Ln}(\mathrm{L})_{3} 100-150^{\circ} \mathrm{C}$.

UDC 930.85

ГРНТИ 03.20
3. По данным ИК спектров определен способ координации лиганда с ионами лантаноидов. Координация лиганда осуществляется только по карбоксильной группе.

4.Наибольшая интенсивность люминесценции наблюдается для комплексных соединений $\mathrm{Eu}^{3+}$, $\mathrm{Tb}^{3+}, \mathrm{Sm}^{3+}$ и $\mathrm{Dy}^{3+}$.

5.На основании анализа спектров люминесценции комплексов изученных лантаноидов с данным лигандом можно предположить одинаковую симметрии центров люминесценции, следовательно, и одинаковую структуру координационного узла.

\section{Литература:}

1.Ельяшевич М.А. Атомная и молекулярная спектроскопия. - М.: Эдиториал УРСС, 2001. - 896 c.

2.Золин В.Ф. Редкоземельный зонд в химии и биологии/ В.Ф. Золин, Л.Д. Коренева, - М.: - Наука, - 1980. - 350 c.

3.Джардималиева Г.И. Макромолекулярные карбоксилаты металлов / Г.И. Джардималиева, А.Д. Помогайло // Успехи химии. - 2013. - Т. 77. - С. 270315.

4. Гарновский А.Д. Современные аспекты синтеза металлокомплексов. Основные лиганды и методы / А.Д. Гарновский, И.С. Васильченко, Д.А. Гарновский. - Ростов-на-Дону: ЛаПо, 2010. - 335 с.

\section{HISTORICAL REASONS OF THE CHINESE KAZAKHS' MIGRATION TO TURKEY AND EUROPE (BASED ON THE SU BEIHAI'S MANUSCRIPT GENERAL HISTORY OF THE KAZAKHS)}

Kaiyrken Tursynkhan Zakonuly ${ }^{1}$, Makhat Danagul Akhmetkarimkyzy ${ }^{2}$

${ }^{1}$ L.N. Gumilyov Eurasian National University, Satpayev Str., 2, 010000 Nur-Sultan, Kazakhstan

Doctor of Historical Sciences, Professor ORCID: 0000-0002-3808-4989

${ }^{2}$ L.N. Gumilyov Eurasian National University, Satpayev Str., 2, 010000 Nur-Sultan, Kazakhstan

Doctor of Historical Sciences, Professor. ORCID: 0000-0002-8038-2680

\section{ИСТОРИЧЕСКИЕ ПРИЧИНЫ ПЕРЕСЕЛЕНИЯ КАЗАХОВ ИЗ КИТАЯ В ТУРЦИЮ И ЕВРОПУ (НА ОСНОВЕ РУКОПИСИ СУ БЭЙХАЯ «ОБЩАЯ ИСТОРИЯ КАЗАХОВ»)}

Кайыркен Турсынхан Законульг ${ }^{1}$, Махат Данагүл Ахметкәрімқызы ${ }^{2}$

${ }^{1}$ Евразийский национальный университет им. Л.Н. Гумилева,

ул. Сатпаева 2, 010000 г. Нур-Султан, Казахстан

Доктор исторических наук, Профессор. ORCID: 0000-0002-3808-4989

${ }^{2}$ Евразийский национальный университет им. Л.Н. Гумилева, ул. Сатпаева 2, 010000 г. Нур-Султан, Казахстан

Доктор исторических наук, Профессор. ORCID: 0000-0002-8038-2680

DOI: $10.31618 /$ ESU.2413-9335.2020.6.76.941

\section{ANNOTATION}

The article presents the reasons for the mass migration of the Kazakhs living in the People's Republic of China to foreign countries in 30`s of twentieth century, including India, Pakistan, Turkey and Europe. The study compares, examines, and correlates different data and the facts in Part IV of the comprehensive study by Chinese scholar Su Beihai General History of the Kazakhs, and the reasons, motivation, circumstances, and fate of the relocation were systematically recorded. Su Beihai saw the nomadic Kazakhs passing through Gansu and Qinghai provinces of China and collected a lot of material about them. Previously, due to strict censorship of the history of 